\title{
Role of miR-21 in the growth and metastasis of human salivary adenoid cystic carcinoma
}

\author{
FEI YAN ${ }^{1}$, CHAO WANG ${ }^{1}$, TING LI $^{1}$, WENYAN CAI ${ }^{2}$ and JINHU SUN $^{3}$ \\ ${ }^{1}$ Department of Oral Medicine, School of Stomatology, Xuzhou Medical University, Xuzhou, Jiangsu 221000; \\ ${ }^{2}$ Department of Stomatology, Children's Hospital Affiliated to Nanjing Medical University, Nanjing, Jiangsu 210000; \\ ${ }^{3}$ Department of Oral and Maxillofacial Surgery, School of Stomatology, Xuzhou Medical University, \\ Xuzhou, Jiangsu 221000, P.R. China
}

Received December 21, 2016; Accepted November 9, 2017

DOI: $10.3892 / \mathrm{mmr} .2018 .8381$

\begin{abstract}
Aberrant microRNA (miRNA/miR) expression has been reported in various cancer types. miR-21, which is considered to be a proto-oncogene and is frequently overexpressed in certain cancer types, has been implicated in tumorigenesis. The aim of the present study was to investigate the effect of miR-21 degradation on tumor progression and its potential mechanisms in human salivary adenoid cystic carcinoma (SACC) development. Results of reverse transcription-quantitative polymerase chain reaction analysis indicated that SACC cells with high metastatic potential (SACC-LM cells) exhibited a significantly higher expression of miR-21 compared with SACC cells with a lower metastatic potential (SACC-83 cells). In addition, following transfection of SACC-LM cells with miR-21 inhibitor, cell viability was reduced, which may be a result of reduced cell proliferation and metastasis, and the induction of apoptosis, as determined by Cell Counting Kit-8, wound healing, Matrigel invasion and flow cytometry assays. Furthermore, bioinformatics analysis indicated that programmed cell death 4 (PDCD4), phosphatase and tensin homolog deleted on chromosome ten (PTEN) and B-cell lymphoma (Bcl)-2 are potential target genes of miR-21. Therefore, western blotting was performed to investigate the expression of these proteins, and the results demonstrated that miR-21 expression level was negatively associated with PDCD4 and PTEN protein expression, and positively associated with Bcl-2 protein expression, in SACC-LM cells, indicating that miR-21 may promote SACC progression via PDCD4, PTEN and Bcl-2. In conclusion, the present study
\end{abstract}

Correspondence to: Professor Jinhu Sun, Department of Oral and Maxillofacial Surgery, School of Stomatology, Xuzhou Medical University, 209 Tongshan Road, Yunlong, Xuzhou, Jiangsu 221000, P.R. China

E-mail:kqxsjh@163.com

Key words: microRNA-21, salivary adenoid cystic carcinoma, proliferation, migration, invasion indicates that miR-21 may be a novel target for SACC therapy and provide a novel basis for the clinical treatment of SACC.

\section{Introduction}

Salivary adenoid cystic carcinoma (SACC) is a malignant tumor that occurs in the large and small salivary glands, accounting for $\sim 7.5-10 \%$ of all salivary malignancies (1). SACC is characterized by its unique biological features, including slow but aggressive growth, high incidence of distant metastasis and a high recurrence rate (2-4). Molecular alterations or biomarkers associated with the development and progression of SACC, in addition to the therapeutic efficacy, are poorly characterized (5). The mortality rate associated with SACC remains high and lung metastasis is the major cause of death (6). As SACC is not sensitive to radiotherapy and chemotherapy, and recurrence is common following surgery, the discovery of appropriate therapeutic targets for the treatment of SACC is required.

MicroRNAs (miRNAs/miRs) belong to a class of non-coding single-stranded RNA molecules that have a length of 22 nucleotides and are encoded by endogenous genes (7). miRNAs participate in the regulation of numerous biological processes by binding to the base sequence of the 3'-untranslated region in target mRNA, which leads to mRNA degradation or translational repression (8). miRNAs are considered to be important regulators of diverse cellular processes. In addition, they may act as oncogenes or anti-oncogenes by altering various cellular pathways (9). Certain miRNAs are abnormally expressed in various cancer types compared with the corresponding normal tissues, including head and neck cancer, breast, lung, colon and stomach cancer, and leukemia and lymphoma (10-12).

Of the various miRNAs that are reported to be involved in cancer development, miR-21 has recently been reported to be overexpressed in SACC (13). In addition, miR-21 upregulation has been observed in various types of malignant tumors compared with their adjacent normal tissue, and accumulating evidence indicates that it may be involved in the regulation of the initiation and development of cancer, which involves cell proliferation, invasion, migration and apoptosis $(14,15)$. Furthermore, miR-21 acts 
as an important regulator in several signaling pathways, including RAS/MEK/extracellular signal-regulated kinase, Wnt/ $\beta$-catenin and phosphatase and tensin homolog deleted on chromosome ten (PTEN)/phosphatidylinositol 3-kinase/AKT, or by targeting programmed cell death 4 (PDCD4), PTEN and TIMP metallopeptidase inhibitor $3(16,17)$. However, the role of miR-21 in SACC and the mechanisms underlying its regulation of this malignant tumor remain unclear.

Therefore, the current study aimed to elucidate the role of miR-21 in the pathological and physiological processes of SACC, and to investigate the underlying mechanisms. Small interfering (si)RNA was employed to reduce miR-21 expression in SACC cells to investigate its role in proliferation, apoptosis, migration and invasion.

\section{Materials and methods}

Cell culture and transfection. Human salivary adenoid cystic carcinoma cell lines with high metastatic potential (SACC-LM) and low metastatic potential (SACC-83) were provided by the Laboratory of Oral and Maxillofacial Surgery, Ninth People's Hospital, School of Medicine, Shanghai Jiao Tong University. Cells were cultured in RPMI-1640 (Hyclone; GE Healthcare Life Sciences, Logan, UT, USA) culture medium containing 10\% fetal bovine serum (FBS; Gibco; Thermo Fisher Scientific, Inc., Waltham, MA, USA), 100 U/ml penicillin and $100 \mu \mathrm{g} / \mathrm{ml}$ streptomycin at $37^{\circ} \mathrm{C}$ in a humidified incubator with $5 \% \mathrm{CO}_{2}$. Upon $70-80 \%$ confluence, using Lipofectamine ${ }^{\circledR} 2000$ (Invitrogen; Thermo Fisher Scientific, Inc.) as transfection medium, miR-21 inhibitor/siRNA (Shanghai GenePharma Co., Ltd., Shanghai, China) or negative control siRNA (Shanghai GenePharma Co., Ltd.) were transfected into SACC-LM cells, according to the manufacturer's protocol. The sequences of miR-21 siRNA and negative control siRNA were 5'-UCAACAUCAGUCUGAUAAGCU A-3' and 5'-CAGUACUUUUGUGUAGUACAA-3', respectively. Non-transfected cells were used as a blank control. The final concentration of siRNA was $60 \mathrm{nM}$. At $5 \mathrm{~h}$ after transfection, the culture medium was replaced with fresh RPMI-1640 containing 10\% FBS and transfection efficiency was determined using fluorescent images.

RNA isolation and reverse transcription-quantitative polymerase chain reaction $(R T-q P C R)$. miRanda (http://34.236.212.39/microrna/home.do), miRBase (http://www.mirbase.org/) and TargetScan (release 7.1) were searched to predicted the target genes of miR-21. At $48 \mathrm{~h}$ after transfection, total RNA and miRNA were extracted using TRIzol reagent (Invitrogen; Thermo Fisher Scientific, Inc.). cDNA was obtained using HiScript Reverse Transcriptase (Vazyme Biotech Co., Ltd., Nanjing, China) including $3.575 \mu \mathrm{g}$ RNA, $2 \mu \mathrm{l}$ Oligo (dT) 15 or $2 \mu \mathrm{l}$ hsa-miR-21-5p loop, $4 \mu \mathrm{l}$ dNTP, $4 \mu 1$ Hiscript Buffer, $1 \mu 1$ Reverse Transcriptase and $0.5 \mu \mathrm{l}$ RNase inhibitor, according to the following protocol: $25^{\circ} \mathrm{C}$ for $5 \mathrm{~min}, 50^{\circ} \mathrm{C}$ for $15 \mathrm{sec}, 85^{\circ} \mathrm{C}$ for $5 \mathrm{~min}$ and $4^{\circ} \mathrm{C}$ for 10 min. mRNA levels of miR-21, PDCD4, PTEN and B-cell lymphoma (Bcl)-2 were detected by qPCR using a SYBR Premix Ex Taq II kit (Takara Bio, Inc., Otsu, Japan) on a 7900HT Fast Real-Time PCR system (Applied Biosystems; Thermo Fisher Scientific, Inc.). Based on the sequence of
miR-21, a stem-loop primer was designed by Primer Premier 5.0 (Premier Biosoft International, Palo Alto, CA, USA) as follows: 5'-GTCGTATCCAGTGCAGGGTCCGAGGTATTC GCACTGGATACGACTCAACATC-3', 5'-TGCGCTAGC TTATCAGACTGA-3' (forward), 5'-CCAGTGCAGGGTCCG AGGTATT-3' (reverse). U6 small nuclear RNA was used as a reference gene, with the primer 5'-CGCTTCGGCAGCACA TATAC-3' (forward); 5'-AAATATGGAACGCTTCACGA-3' (reverse). The following other primer sequences were used: PDCD4, 5'-AACCAGTCC-AAAGGGAAGG-3' (forward) and 5'-ACATCCACCTCCTCCACATC-3' (reverse); PTEN, 5'-CACGACGGGAAGACAAGTTC-3' (forward) and 5'-TCT GCACGCTCTATACTGCA-3' (reverse); and Bcl-2, 5'-AGC CTGAGAGCAACCCAAT-3' (forward) and 5'-AGCGAC GAGAGAAGTCATCC-3' (reverse). GAPDH was used as an internal reference, the sequences were 5'-TCAAGAAGG TGGTGAAGCAGG-3' (forward); 5'-TCAAAGGTGGAG GAGTGGGT-3' (reverse). The PCR reaction was performed as follows: $95^{\circ} \mathrm{C}$ for $30 \mathrm{sec}$, followed by 40 cycles at $95^{\circ} \mathrm{C}$ for $5 \mathrm{sec}$ and $60^{\circ} \mathrm{C}$ for $30 \mathrm{sec}$. All RT-qPCR experiments were performed in triplicate and repeated three times. Each gene expression was quantified using the $2^{-\Delta \Delta \mathrm{Cq}}$ method (18), and their expression was compared between cells transfected with negative control and miR-21 siRNA.

Cell proliferation and viability assay. A Cell Counting Kit (CCK)-8 assay was performed to measure cell proliferation and viability. SACC-LM cells were seeded at a density of $8 \times 10^{3}$ cells/well in $96-$ well plates. When the cells reached $70-80 \%$ confluence, they were transfected with miR-21 inhibitor or negative control and incubated for $24,48,72$ or 96 h. Subsequently, $10 \mu \mathrm{l}$ CCK-8 reagent (Dojindo Molecular Technologies, Inc., Kumamoto, Japan) was added into each well of the plate and cells were incubated at $37^{\circ} \mathrm{C}$ for $30 \mathrm{~min}$. Absorbance at $460 \mathrm{~nm}$ was measured using a microplate reader (BioTek Instruments, Inc., Winooski, VT, USA).

Wound healing assay. A total of $5 \times 10^{5}$ SACC-LM cells per well were seeded into 6-well plates and cultured until $80 \%$ confluence. At $48 \mathrm{~h}$ after transfection, a wound was created in the center of the layer of confluent cells adhering to the bottom of the well using a $100 \mu 1$ pipette tip. Plates were gently washed three times with PBS to remove the cell debris, and serum-free RPMI-1640 medium was added. The scratch width was measured by photo recordings at 0 and $24 \mathrm{~h}$ after the wound was created using an inverted optical microscope at x100 magnification (Olympus Corporation, Tokyo, Japan).

Matrigel invasion assay. Cell invasion was detected by a Matrigel invasion assay. Diluted Matrigel (100 $\mu \mathrm{l}$; BD Biosciences, Franklin Lakes, NJ, USA) was added to the upper chamber of each well of a 24-well Transwell plate (Corning Incorporated, Corning, NY, USA). At $48 \mathrm{~h}$ after transfection, $1 \times 10^{5}$ SACC-LM cells in $200 \mu 1$ serum-free RPMI-1640 medium were seeded in the upper chamber, while $500 \mu 1$ RPMI-1640 containing 10\% FBS was added to the lower chamber. After $24 \mathrm{~h}$ incubation at $37^{\circ} \mathrm{C}$, residual cells in the upper chamber were carefully removed with a cotton swab, while cells that had invaded to the lower chamber were fixed using $4 \%$ paraformaldehyde for $20 \mathrm{~min}$ and stained with $0.1 \%$ 
A

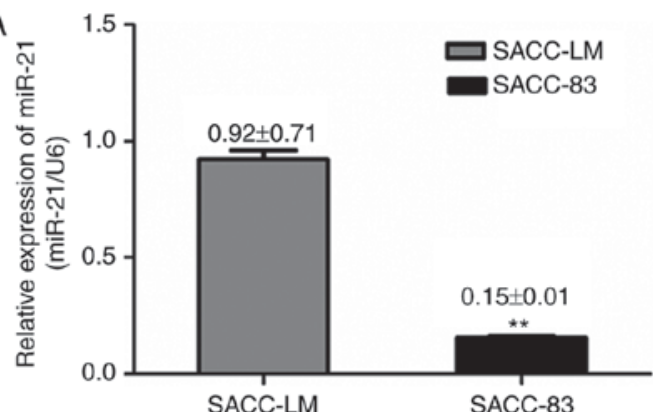

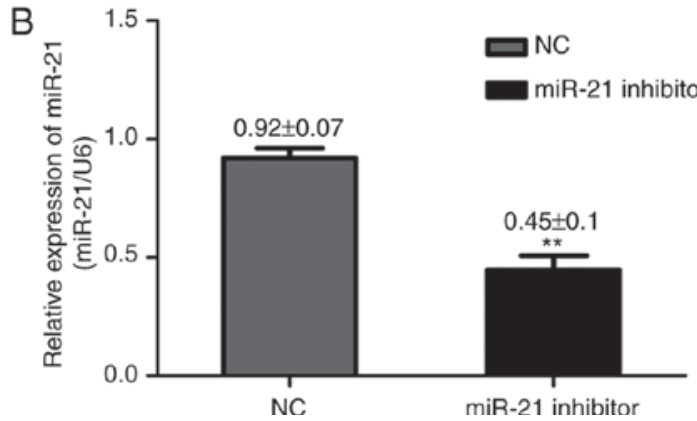

Figure 1. miR-21 expression in SACC cell lines. (A) miR-21 was significantly higher in SACC-LM cells compared with SACC-83 cells, as determined by RT-qPCR. ${ }^{* *} \mathrm{P}<0.01$ vs. SACC-LM cell line. (B) miR-21 expression in SACC-LM cells following transfection with miR-21 siRNA and NC siRNA, as determined by RT-qPCR. ${ }^{* *} \mathrm{P}<0.01$ vs. NC group. All data were normalized to the expression of endogenous control U6. miR, microRNA; SACC, salivary adenoid cystic carcinoma; RT-qPCR, reverse transcription-quantitative polymerase chain reaction; siRNA, small interfering RNA; NC, negative control; U6, U6 small nuclear RNA; miR-21 inhibitor, siRNA targeting miR-21.

crystal violet for $15 \mathrm{~min}$ at room temperature. Cells on the bottom surface were quantified by counting five random fields per well under the light microscope at a magnification of x100 using Image-Pro Plus version 6.0 (Media Cybernetics, Inc., Rockville, MD, USA), and the mean number of cells passing through the chamber calculated.

Flow cytometry. At $48 \mathrm{~h}$ after transfection, transfected and non-transfected SACC-LM cells were harvested by trypsinization and washed twice in cold PBS. Subsequently, 1.0x $10^{5}$ cells were suspended in $500 \mu \mathrm{l}$ binding buffer containing $5 \mu \mathrm{l}$ annexin V- FITC (Nanjing KeyGen Biotech Co., Ltd.) and $5 \mu \mathrm{l}$ propidium iodide (PI; all from Nanjing KeyGen Biotech Co., Ltd., Nanjing, China), gently mixed with a pipette and incubated at room temperature for $15 \mathrm{~min}$. The apoptotic rate was obtained from the percentage of cells that were double-stained with annexin V-FITC and PI, as detected by a flow cytometer (Facs Canto II; BD Biosciences) using BD FACSDiva version 8.0.1 software.

Western blot analysis. Then, $48 \mathrm{~h}$ after transfection, nontransfected and transfected SACC-LM cells were trypsinized, collected and centrifuged at $671 \mathrm{x} \mathrm{g}$ for $5 \mathrm{~min}$ at room temperature. Total protein was extracted using protein lysis solution containing RIPA buffer and 1\% phenyl methane sulfonyl fluoride (PMSF; Beyotime Institute of Biotechnology, Jiangsu, China). Protein concentrations were measured using a BCA Protein assay kit (Beyotime Institute of Biotechnology). Denatured protein samples $(40 \mu \mathrm{g})$ were separated by $10 \%$ SDS-PAGE and subsequently transferred to polyvinylidene fluoride membranes. After blocking in 5\% nonfat dry milk for $2 \mathrm{~h}$ at room temperature, the corresponding membranes were incubated with antibodies against PDCD4 (ab80590; 1:7,000; Abcam, Cambridge, UK), Bcl-2 (ab32124; 1:1,000; Abcam), PTEN (ab32199; 1:1,000; Abcam), Snail family transcriptional repressor 1 (Snail1; BZ06198; 1:500; Bioworld Technology, Inc., St. Louis Park, MN, USA) and E-cadherin (BS1098; 1:500; Bioworld Technology, Inc.) at $4^{\circ} \mathrm{C}$ overnight. GAPDH (BZ00672; 1:7,000; Bioworld Technology, Inc.) was used as an internal control. Subsequently, the membranes were incubated with goat anti-rabbit polyclonal IgG secondary antibodies (ZB-2010; 1:500; OriGene Technologies, Inc., Beijing, China) for $2 \mathrm{~h}$ at room temperature. Membranes were washed in washing buffer three times and PDCD4, PTEN, Bcl-2, Snail1, E-cadherin and GAPDH protein bands were visualized using a BCIP/NBT Alkaline Phosphatase Color Development kit (P0321; Beyotime Institute of Biotechnology). Western blot results were normalized to the expression of GAPDH and analyzed using ImageJ version 1.49 software (National Institutes of Health, Bethesda, MD, USA).

Statistical analysis. Data were analyzed using SPSS statistical software version 16.0 (SPSS, Inc., Chicago, IL, USA). Results are presented as the mean \pm standard deviation. Comparisons between two groups were performed using Student's t-test, while comparisons among multiple groups were performed using one-way analysis of variance followed by LSD test. $\mathrm{P}<0.05$ was considered to indicate a statistically significant difference.

\section{Results}

miR-21 is overexpressed in SACC cell lines and may be associated with tumor metastasis. Previous reports have indicated that miR-21 expression in SACC tumor tissue samples was significantly higher compared with normal tissue samples (13). In order to investigate the potential role of miR-21 in SACC, the present study measured miR-21 expression in two SACC cell lines (SACC-83 and SACC-LM). RT-qPCR results demonstrated that miR-21 expression was significantly higher in SACC-LM cells, which have a high metastatic potential, compared with SACC-83 cells, which have a low metastatic potential (Fig. 1A), indicating a potential role of miR-21 in SACC cells metastatic ability.

miR-21 downregulation inhibits tumor proliferation and induces apoptosis. To investigate the effect of miR-21 on cell growth, cells were transfected with miR-21 siRNA or negative control siRNA. RT-qPCR analysis revealed that miR-21 expression was reduced in SACC-LM cells transfected with miR-21 siRNA, compared with cells transfected with negative control siRNA (Fig. 1B). Flow cytometry and CCK-8 assays were performed to determine the effect of miR-21 silencing on cell apoptosis and proliferation in SACC-LM cells, respectively. CCK-8 detection was performed at five time points $(0,24,48,72$ and $96 \mathrm{~h})$. The apoptotic rate in the miR-21 siRNA, negative control siRNA and blank control groups was 
A

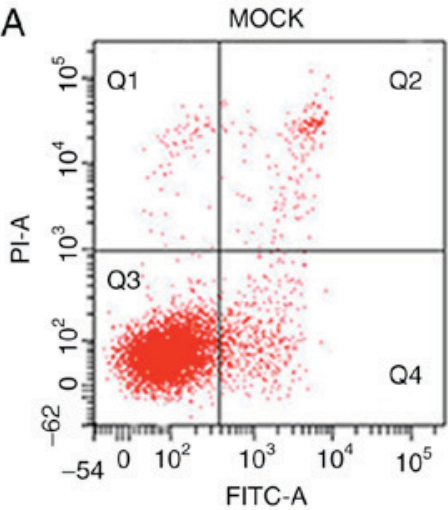

B

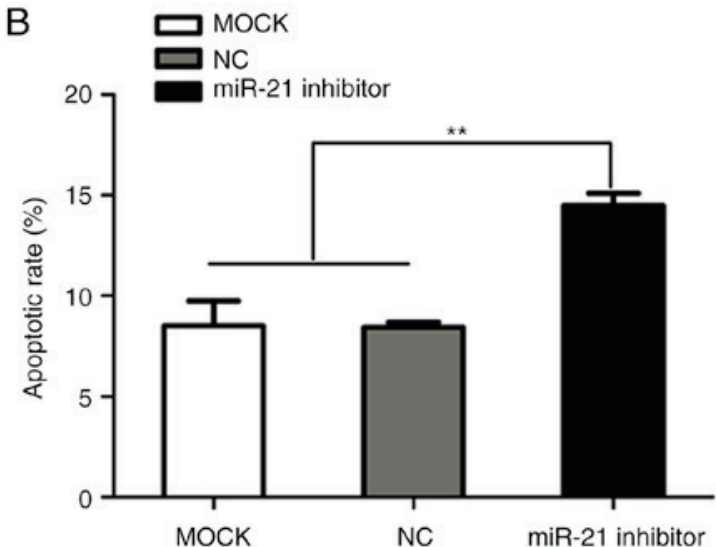

NC

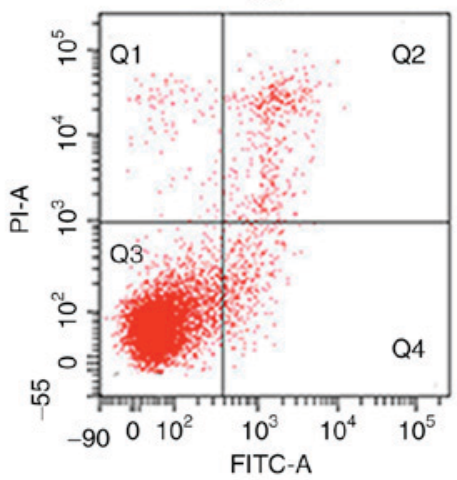

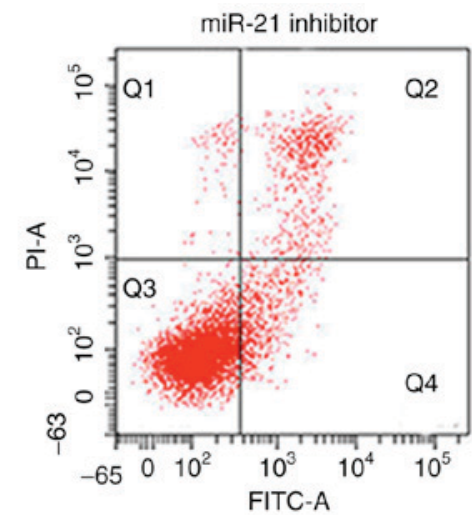

C

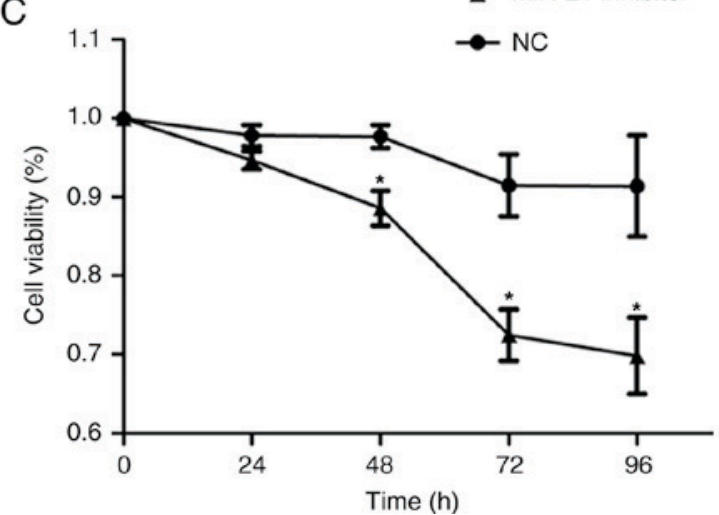

Figure 2. Effect of miR-21 siRNA on SACC-LM proliferation and apoptosis. (A) Representative flow cytometry plots for blank control cells, and cells transfected with NC and miR-21 siRNA. Cell apoptosis was measured by annexin V-FITC/PI staining and flow cytometry (apoptotic cells refer to the cells in Q2 and Q4 quadrants). (B) miR-21 siRNA transfection significantly increased SACC-LM apoptosis compared with the control groups. ${ }^{* *} \mathrm{P}<0.01$, as indicated. (C) Proliferation of SACC-LM cells at 0,24, 48, 72 and $96 \mathrm{~h}$ after transfection with NC or miR-21 siRNA was measured by a Cell Counting Kit-8 assay. ${ }^{*} \mathrm{P}<0.05$, as indicated. miR, microRNA; siRNA, small interfering RNA; SACC, salivary adenoid cystic carcinoma; NC, negative control; FITC, fluorescein isothiocyanate; PI, propidium iodide; MOCK, blank control; miR-21 inhibitor, siRNA targeting miR-21.

$14.5 \pm 0.6,8.43 \pm 0.25$ and $8.5 \pm 1.249 \%$, respectively. In addition, miR-21 siRNA-transfected cells exhibited a significant increase in annexin $\mathrm{V}$ staining compared with the two other groups ( $\mathrm{P}<0.01$; Fig. $2 \mathrm{~A}$ and $\mathrm{B})$. As demonstrated in Fig. $2 \mathrm{C}$, miR-21 silencing triggered a decreased cell viability $(\mathrm{P}<0.05)$ compared with cells transfected with negative control siRNA, and viability was decreased in a time-dependent manner.

miR-21 promotes SACC migration and invasion. Wound healing migration and Matrigel invasion assays were performed to investigate the effects of miR-21 on cell migration and invasion, respectively. Based on the wound healing assay results, transfection with miR-21 siRNA significantly reduced the migratory ability of SACC-LM cells, compared with cells transfected with negative control siRNA (Fig. 3A and B). In the Matrigel invasion assay, miR-21 silencing in SACC-LM cells reduced the number of cells crossing the membrane, compared with the negative control siRNA group, with means of 675 and 269 cells per random microscopic field, respectively (Fig. 3C and D). Furthermore, the protein expression of metastasis-associated markers was determined by western blot analysis, and the results demonstrated that Snail1 protein expression was decreased, while E-cadherin protein expression was increased, in the miR-21 siRNA group compared with blank control and negative control siRNA groups (Fig. 3E and F). These results indicate that miR-21 may promote cell invasion and migration in SACC-LM cells, which may be associated with the high potential for metastasis of this cell line.

PDCD4, PTEN and Bcl-2 are target genes of $m i R-21$ in $S A C C$. To identify potential target genes of miR-21, several databases were employed, including miRanda, miRBase and TargetScan. The search results indicated that PDCD4, PTEN and Bcl-2 are predicted miR-21 target genes. Therefore, RT-qPCR was performed to further verify the accuracy of the above result. The results demonstrated that PDCD4 and PTEN mRNA levels were upregulated, while Bcl-2 mRNA levels were downregulated, following transfection of SACC-LM cells with miR-21 siRNA, compared with cells transfected with negative control siRNA (Fig. 4A). Therefore, these results demonstrated a potential role for miR-21 in the regulation of the expression of PDCD4, PTEN and Bcl-2.

miR-21 regulates tumor growth and metastasis by targeting PDCD4, PTEN and Bcl-2 in SACC. As PDCD4, PTEN and $\mathrm{Bcl}-2$ are involved in migration, invasion and apoptosis and they are miR-21 target genes, western blot analysis was performed to further determine whether miR-21 regulates the protein expression of these genes in SACC-LM cells. The results demonstrated that transfection of SACC-LM cells with miR-21 siRNA led to a significant increase in PDCD4 and PTEN protein expression, and markedly reduced Bcl-2 protein 

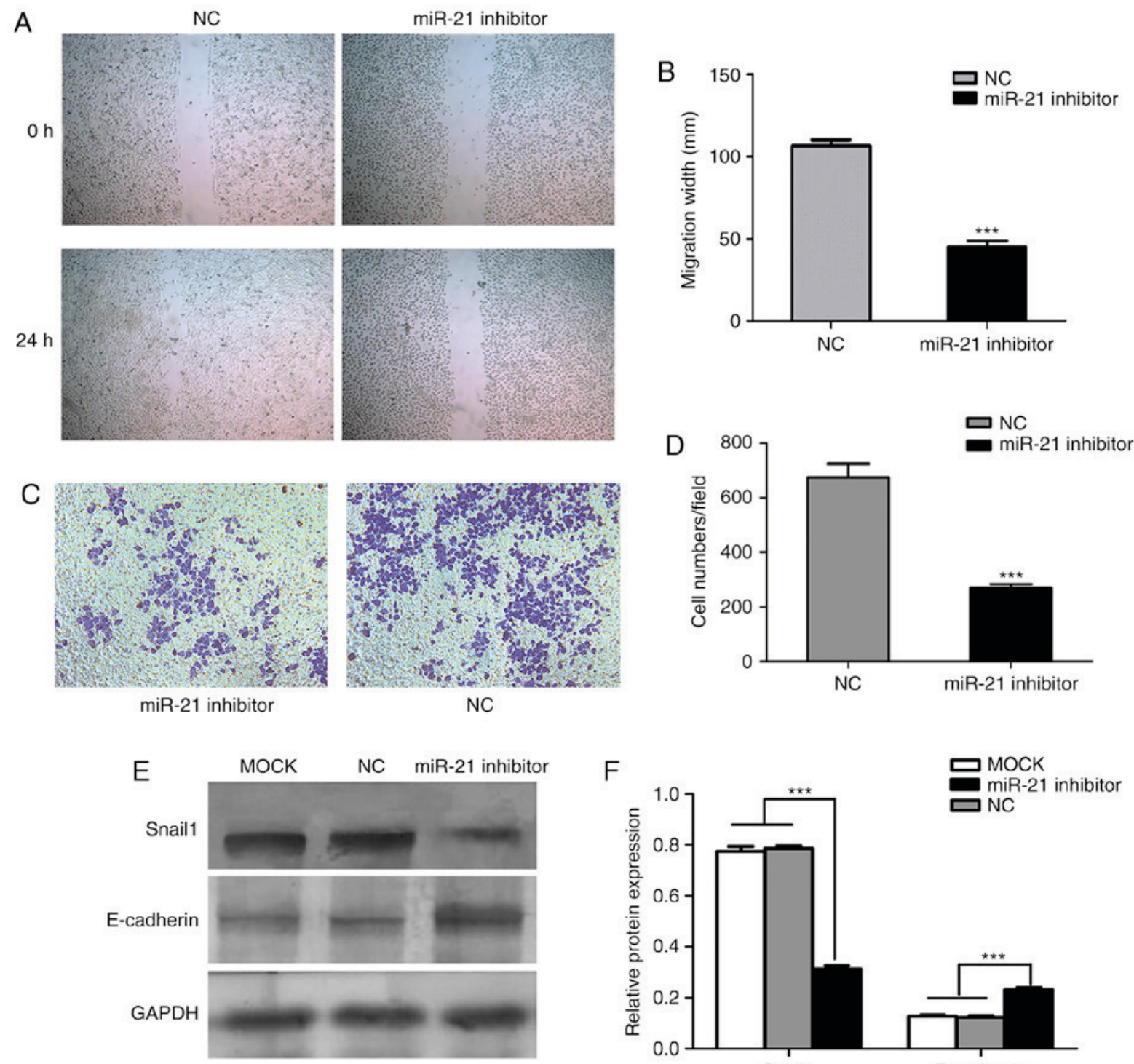

F

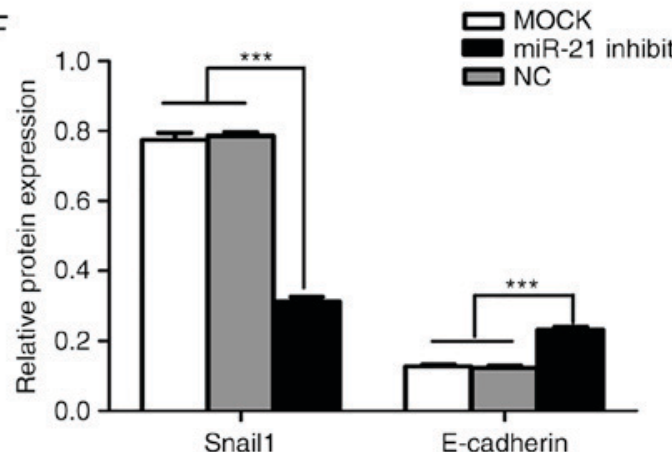

Figure 3. Effects of miR-21 on SACC-LM migration and invasion. (A) SACC-LM cell migration was measured by a wound healing assay following transfection with NC or miR-21 siRNA. Magnification, x100. (B) Quantification of SACC-LM cell migration at $24 \mathrm{~h}$ after the wound was created in NC and miR-21 siRNA-transfected cells. ${ }^{* * *} \mathrm{P}<0.001$ vs. NC group. (C) Cell invasion was measured by a Matrigel invasion assay. Magnification, $\mathrm{x} 100$. (D) Quantification of NC and miR-21 siRNA-transfected SACC-LM cells crossing the Matrigel-coated membrane following incubation for $24 \mathrm{~h} .{ }^{* * *} \mathrm{P}<0.001 \mathrm{vs}$. NC group. (E) Western blotting was performed to investigate Snaill and E-cadherin protein expression in blank control, and NC and miR-21 siRNA-transfected SACC-LM cells. Representative bands are presented. (F) Snaill protein expression was significantly decreased, while E-cadherin protein expression was increased, following transfection of SACC-LM cells with miR-21 siRNA, compared with the control groups. Protein expression was normalized to GAPDH expression. ${ }^{* * *} \mathrm{P}<0.001$, as indicated. miR, microRNA; SACC, salivary adenoid cystic carcinoma; NC, negative control; siRNA, small interfering RNA; Snail1, snail family transcriptional repressor 1; miR-21 inhibitor, siRNA targeting miR-21; MOCK, blank control.

expression, compared with blank control and negative control siRNA groups (Fig. 4B and C). These results indicate that miR-21 levels were negatively associated with PDCD4 and PTEN expression, and positively associated with Bcl-2 expression. Therefore, miR-21 may reduce apoptosis, and increase cell proliferation and metastasis, by regulating the expression of PDCD4, PTEN and Bcl-2 in SACC.

\section{Discussion}

SACC is a common malignant tumor of the head and neck that has a distinct potential for invasion and distant migration. At present, few studies have investigated the molecular markers that are associated with SACC treatment and prognosis $(19,20)$. In recent years, an association between various miRNAs and tumor development has been established and substantial progress has been made concerning the biological function of miRNAs and their clinical relevance in cancer (21-24) Previous studies employed miRNA microarrays and RT-qPCR to determine miRNA expression profiles in SACC cell lines with different metastatic potentials $(13,25)$. These reports demonstrated that miR-4487, miR-4430, miR-486-3p, miR-5191, miR-21 and miR-18a may be involved in the progression of SACC. Notably, miR-21 is a key factor in multiple malignancy-associated processes; it triggers the inflammatory response leading to tumor growth and metastasis, and promotes the interaction between tumor cells and the microenvironment, therefore promoting 

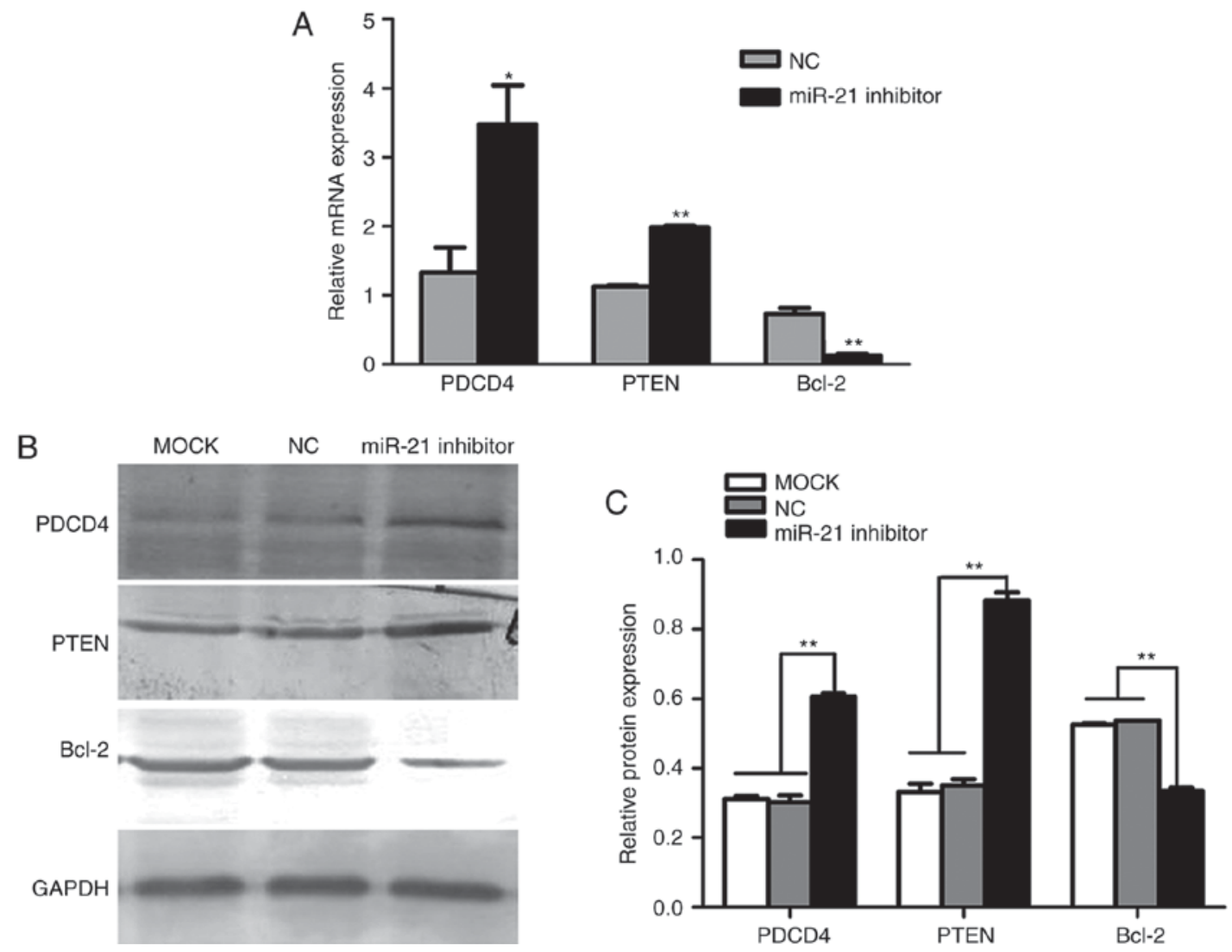

Figure 4. Effects of miR-21 on PDCD4, PTEN and Bcl-2 mRNA and protein expression. (A) Reverse transcription-quantitative polymerase chain reaction results demonstrated that PDCD4 and PTEN mRNA were significantly increased, while Bcl-2 mRNA was decreased, when endogenous miR-21 was silenced using miR-21-targeting siRNA. ${ }^{\mathrm{P}}<0.05$ and ${ }^{* *} \mathrm{P}<0.01$ vs. NC siRNA group. (B) Protein levels of PDCD4, PTEN and Bcl-2 were detected by western blotting. Representative bands are presented. (C) PDCD4 and PTEN protein expression was significantly increased, while Bcl-2 protein expression was decreased, when endogenous miR-21 was silenced using miR-21 siRNA in SACC-LM cells. Protein expression was normalized to GAPDH protein expression. "* P<0.01, as indicated. miR, microRNA; PDCD4, programmed cell death 4; PTEN, phosphatase and tensin homolog deleted on chromosome ten; Bcl-2, B-cell lymphoma-2; siRNA, small interfering RNA; SACC, salivary adenoid cystic carcinoma; NC, negative control; miR-21 inhibitor, siRNA targeting miR-21; MOCK, blank control.

tumor occurrence and development (26-28). However, the underlying molecular mechanism of miR-21 action requires further investigation.

In the present study, miR-21 expression was significantly upregulated in the SACC-LM cell line (high metastatic potential) compared with the SACC-83 cell line (low metastatic potential), which indicated that the SACC-LM cell line is more suitable for the investigation of miR-21. Downregulation of miR-21 expression using siRNA led to significantly reduced cell migration and invasion, and increased apoptosis, while cell viability was inhibited to a certain extent, compared with negative control siRNA-transfected cells. Overall, these results indicated that miR-21 may have various roles in tumor development and may be considered an important oncomiR in SACC.

By searching several databases, PDCD4, PTEN and Bcl-2 were considered to be potential targets of miR-21. PDCD4 is a novel tumor suppressor gene that was recently discovered and has been reported to be involved in the regulation of tumor development and metastasis (29). PDCD4 is frequently downregulated in various tumor tissues and cells, which is associated with increased cell proliferation, migration and invasion, and decreased apoptosis $(30,31)$. Previous studies have demonstrated that PDCD4 expression was negatively associated with miR-21 levels in gastric cancer $(32,33)$. Bcl-2, as an anti-apoptotic gene, is able to repress various apoptotic death events. A previous report demonstrated that miR-21 inhibited apoptosis through regulation of Bcl-2 in a breast cancer mouse model (34), while Shi et al (35) reported that miR-21 overexpression upregulated Bcl-2 expression in human glioblastoma U-87MG cells. The results of the present study demonstrated that transfection of SACC-LM cells with miR-21 siRNA resulted in a higher apoptotic rate, which may be due to the downregulation of Bcl-2 and upregulation of PDCD4 at mRNA and protein levels. Therefore, a negative association was observed between miR-21 and PDCD4 protein levels in SACC-LM cells, while a positive association was observed between miR-21 and Bcl-2 expression. These results indicate that miR-21 may suppress cell apoptosis by regulating the expression of PDCD4 and Bcl-2.

PTEN, which is an established tumor suppressor gene, has important roles in various tumor processes, including cell growth, apoptosis, adhesion, migration and infiltration $(36,37)$. Genetic inactivation of PTEN is frequently observed in glioblastoma, endometrial cancer and prostate cancer, and reduced PTEN expression has been reported in various other cancer types, including lung and breast cancer (37-39). Liu et al (40) reported that the expression of PTEN was reduced in $>80 \%$ of 
solid SACC cases, and PTEN was also reported to be closely associated with the prognosis and lymph node metastasis of salivary gland cancer (41). In the current study, miR-21 downregulation led to increased PTEN expression, and PTEN protein expression was negatively associated with cell migration and invasion in SACC-LM cells. Epithelial-mesenchymal transition (EMT) is a basic process of embryonic development that involves the separation and migration of epithelial cells from epithelial tissue to other locations, and is the foundation for normal development, wound healing and malignant epithelial tumors (42). Among various EMT regulatory factors, Snail1 is considered to be a key factor in tumor metastasis associated with EMT by directly repressing the expression of the epithelial cell marker, E-cadherin (43). In the present study, western blot analysis confirmed that downregulation of miR-21 resulted in decreased protein expression of Snail1, which may therefore lead to reduced cell migration and invasion, in SACC-LM cells. Furthermore, E-cadherin protein levels were significantly increased following miR-21 silencing, compared with the control groups. These data indicate that miR-21 may control PTEN and Snail1 protein expression to further regulate the metastasis and invasion of SACC cells.

In conclusion, the results of the current study indicated that miR-21 may be considered as a potential prognostic biomarker for SACC and may have potential as a therapeutic agent for the treatment of SACC.

\section{Acknowledgements}

The present study was supported by the National Natural Science Foundation of China (grant nos. 31060167 and 81160242), the 'Qing Lan Project' of the Jiangsu Higher Education Institutions Young and Middle-aged Academic Leaders Funded Project (grant no. 51934) and the Outstanding Talent Fund Project of Xuzhou Medical College (grant no. 2013012). The authors thank the Laboratory of Oral and Maxillofacial Surgery, Ninth People's Hospital, School of Medicine, Shanghai Jiao Tong University (Shanghai, China) for providing the SACC-83 and SACC-LM cell lines.

\section{References}

1. Liu X, Zhang W, Guo H, Yue J and Zhuo S: miR-98 functions as a tumor suppressor in salivary adenoid cystic carcinomas. Onco Targets Ther 9: 1777-1786, 2016.

2. Tang Y, Liang X, Zheng M, Zhu Z, Zhu G, Yang J and Chen Y: Expression of c-kit and Slug correlates with invasion and metastasis of salivary adenoid cystic carcinoma. Oral Oncol 46: 311-316, 2010.

3. He JF, Ge MH, Zhu X, Chen C, Tan Z, Li YN and Gu ZY: Expression of RUNX3 in salivary adenoid cystic carcinoma: Implications for tumor progression and prognosis. Cancer Sci 99 : 1334-1340, 2008.

4. Hu K, Gan YH, Li SL, Gao Y, Wu DC, Wang CY and Yu GY: Relationship of activated extracellular signal-regulated kinase $1 / 2$ with lung metastasis in salivary adenoid cystic carcinoma. Oncology Rep 21: 137-143, 2009.

5. Qian X, Kaufmann AM, Chen C, Tzamalis G, Hofmann VM, Keilholz U, Hummel $M$ and Albers AE: Prevalence and associated survival of high-risk HPV-related adenoid cystic carcinoma of the salivary glands. Int J Oncol 49: 803-811, 2016.

6. Li S, Zhang X, Zhou Z, Huang Z, Liu L and Huang Z: Downregulation of nucleophosmin expression inhibited proliferation and induced apoptosis in salivary gland adenoid cystic carcinoma. J Oral Pathol Med 46: 175-181, 2016.
7. Sun L, Liu B, Lin Z, Yao Y, Chen Y, Li Y, Chen J, Yu D, Tang Z, Wang B, et al: miR-320a acts as a prognostic factor and Inhibits metastasis of salivary adenoid cystic carcinoma by targeting ITGB3. Mol Cancer 14: 96, 2015.

8. Dong YL, Zhou L, Li YL, Xiao K and Weng XS: Establishment and assessment of rat models of glucocorticoid-induced osteonecrosis. Zhongguo Yi Xue Ke Xue Yuan Xue Bao 37: 152-156, 2015.

9. Mirzaei H, Gholamin S, Shahidsales S, Sahebkar A, Jaafari MR, Mirzaei HR, Hassanian SM and Avan A: MicroRNAs as potential diagnostic and prognostic biomarkers in melanoma. Eur J Cancer 53: 25-32, 2016.

10. Yu F, Yao H, Zhu P, Zhang X, Pan Q, Gong C, Huang Y, Hu X, $\mathrm{Su}$ F, Lieberman J and Song E: let-7 regulates self renewal and tumorigenicity of breast cancer cells. Cell 131: 1109-1123, 2007.

11. Couzin J: Cancer biology. A new cancer player takes the stage. Science 310: 766-767, 2005

12. Liu MX, Zhou KC and Cao Y: MCRS1 overexpression, which is specifically inhibited by $\mathrm{miR}-129^{*}$, promotes the epithelial-mesenchymal transition and metastasis in non-small cell lung cancer. Mol Cancer 13: 245, 2014.

13. Jiang LH, Ge MH, Hou XX, Cao J, Hu SS, Lu XX, Han J, Wu YC, Liu X, Zhu X, et al: miR-21 regulates tumor progression through the miR-21-PDCD4-Stat3 pathway in human salivary adenoid cystic carcinoma. Lab Invest 95: 1398-1408, 2015.

14. Martin del Campo SE, Latchana N, Levine KM, Grignol VP, Fairchild ET, Jaime-Ramirez AC, Dao TV, Karpa VI, Carson M, Ganju A, et al: miR-21 enhances melanoma invasiveness via inhibition of tissue inhibitor of metalloproteinases 3 expression: In vivo effects of miR-21 inhibitor. PLoS One 10: e0115919, 2015.

15. Leone E, Morelli E, Di Martino MT, Amodio N, Foresta U, Gullà A, Rossi M, Neri A, Giordano A, Munshi NC, et al: Targeting miR-21 inhibits in vitro and in vivo multiple myeloma cell growth. Clin Cancer Res 19: 2096-2106, 2013.

16. Yu Y, Kanwar SS, Patel BB, Oh PS, Nautiyal J, Sarkar FH and Majumdar AP: MicroRNA-21 induces stemness by downregulating transforming growth factor beta receptor 2 (TGF $\beta R 2$ ) in colon cancer cells. Carcinogenesis 33: 68-76, 2012.

17. Zhang BG, Li JF, Yu BQ, Zhu ZG, Liu BY and Yan M: microRNA-21 promotes tumor proliferation and invasion in gastric cancer by targeting PTEN. Oncol Rep 27: 1019-1026, 2012.

18. Livak KJ and Schmittgen TD: Analysis of relative gene expression data using real-time quantitative PCR and the 2(-Delta Delta $\mathrm{C}(\mathrm{T}))$ method. Methods 25: 402-408, 2001.

19. Chen W, Liu BY, Zhang X, Zhao XG, Cao G, Dong Z and Zhang SL: Identification of differentially expressed genes in salivary adenoid cystic carcinoma cells associated with metastasis. Arch Med Sci 12: 881-888, 2016.

20. Feng X, Matsuo K, Zhang T, Hu Y, Mays AC, Browne JD, Zhou X and Sullivan CA: MicroRNA profiling and target genes related to metastasis of salivary adenoid cystic carcinoma. Anticancer Res 37: 3473-3481, 2017.

21. Cai L, Chen Q, Fang S, Lian M and Cai M: MicroRNA-329 inhibits cell proliferation and tumor growth while facilitates apoptosis via negative regulation of KDM1A in gastric cancer. J Cell Biochem: Nov 11, 2017. Doi: 10.1002/jcb.26497.

22. Rammer M, Webersinke G, Haitchi-Petnehazy S, Maier E, Hackl H, Charoentong P, Malli T, Steinmair M, Petzer AL and Rumpold H: MicroRNAs and their role for T stage determination and lymph node metastasis in early colon carcinoma. Clin Exp Metastasis: Nov 13, 2017. Doi: 10.1007/s10585-017-9863-9.

23. Fu LL, Li CJ, Xu Y, Li LY, Zhou X, Li DD, Chen SX, Wang FG, Zhang XY and Zheng LW: Role of lncRNAs as novel biomarkers and therapeutic targets in ovarian cancer. Crit Rev Eukaryot Gene Expr 27: 183-195, 2017.

24. Takahasi K, Iinuma $H$, Wada $K$, Minezaki S, Kawamura S, Kainuma M, Ikede Y, Shibuya M, Miura F and Sano K: Usefulness of exosome-encapsulated microRNA-451a as a minimally invasive biomarker for prediction of recurrence and prognosis in pancreatic ductal adenocarcinoma. J Hepatobiliary Pancreat Sci: Nov 11, 2017. Doi: 10.1002/jhbp.524.

25. Chen W, Zhao X, Dong Z, Cao G and Zhang S: Identification of microRNA profiles in salivary adenoid cystic carcinoma cells during metastatic progression. Oncol Lett 7: 2029-2034, 2014.

26. Shi GH, Ye DW, Yao XD, Zhang SL, Dai B, Zhang HL, Shen YJ, Zhu Y, Zhu YP, Xiao WJ and Ma CG: Involvement of microRNA-21 in mediating chemo-resistance to docetaxel in androgen-independent prostate cancer PC3 cells. Acta Pharmacol Sin 31: 867-873, 2010. 
27. Alder H, Taccioli C, Chen H, Jiang Y, Smalley KJ, Fadda P, Ozer HG, Huebner K, Farber JL, Croce CM and Fong LY: Dysregulation of miR-31 and miR-21 induced by zinc deficiency promotes esophageal cancer. Carcinogenesis 33: 1736-1744, 2012.

28. Connolly EC, Van Doorslaer K, Rogler LE and Rogler CE: Overexpression of miR-21 promotes an in vitro metastatic phenotype by targeting the tumor suppressor RHOB. Mol Cancer Res 8: 691-700, 2010.

29. Liao J, Liu R, Shi YJ, Yin LH and Pu YP: Exosome-shuttling microRNA-21 promotes cell migration and invasion-targeting PDCD4 in esophageal cancer. Int J Oncol 48: 2567-2579, 2016.

30. Ma G, Zhang H, Dong M, Zheng X, Ozaki I, Matsuhashi S and Guo K: Downregulation of programmed cell death 4 (PDCD4) in tumorigenesis and progression of human digestive tract cancers. Tumor Biol 34: 3879-3885, 2013.

31. Wang D, Guo S, Han SY, Xu N, Guo JY and Sun Q: Distinct roles of different fragments of PDCD4 in regulating the metastatic behavior of B16 melanoma cells. Int J Oncol 42: $1725-1733,2013$

32. Motoyama K, Inoue $\mathrm{H}$, Mimori K, Tanaka F, Kojima $\mathrm{K}$, Uetake H, Sugihara K and Mori M: Clinicopathological and prognostic significance of PDCD4 and microRNA-21 in human gastric cancer. Int J Oncol 36: 1089-1095, 2010.

33. Cao Z, Yoon JH, Nam SW, Lee JY and Park WS: PDCD4 expression inversely correlated with miR-21 levels in gastric cancers. J Cancer Res Clin Oncol 138: 611-619, 2012.

34. Asangani IA, Rasheed SA, Nikolova DA, Leupold JH, Colburn NH, Post S and Allgayer H: MicroRNA-21 (miR-21) post-transcriptionally downregulates tumor suppressor Pded 4 and stimulates invasion, intravasation and metastasis in colorectal cancer. Oncogene 27: 2128-2136, 2008.

35. Shi L, Chen JA, Yang JA, Pan TH, Zhang SG and Wang ZM: miR-21 protected human glioblastoma U87MG cells from chemotherapeutic drug temozolomide induced apoptosis by decreasing Bax/Bcl-2 ratio and caspase-3 activity. Brain Res 1352: 255-264, 2010 .
36. Sizemore GM, Balakrishnan S, Hammer AM, Thies KA, Trimboli AJ, Wallace JA, Sizemore ST, Kladney RD, Woelke SA, Yu L, et al: Stromal PTEN inhibits the expansion of mammary epithelial stem cells through Jagged-1. Oncogene 36: 2297-2308, 2017.

37. Upton DH, Walters KA, Allavena RE, Jimenez M, Desai R, Handelsman DJ and Allan CM: Global or granulosa cell-specific pten mutations in combination with elevated fsh levels fail to cause ovarian tumours in mice. Horm Cancer 7: 316-326, 2016.

38. Krohn A, Diedler T, Burkhardt L, Mayer PS, De Silva C, Meyer-Kornblum M, Kötschau D, Tennstedt P, Huang J, Gerhäuser C, et al: Genomic deletion of PTEN is associated with tumor progression and early PSA recurrence in ERG fusion-positive and fusion-negative prostate cancer. Am J Pathol 181: 401-412, 2012.

39. Xue X, Liu Y, Wang Y, Meng M, Wang K, Zang X, Zhao S, Sun X, Cui L, Pan L and Liu S: miR-21 and miR-155 promote non-small cell lung cancer progression by downregulating SOCS1, SOCS6, and PTEN. Oncotarget 7: 84508-84519, 2016.

40. Liu H, Du L, Wang R, Wei C, Liu B, Zhu L, Liu P, Liu Q, Li J, Lu SL and Xiao J: High frequency of loss of PTEN expression in human solid salivary adenoid cystic carcinoma and its implication for targeted therapy. Oncotarget 6: 11477-11491, 2015.

41. Ettl T, Gosau M, Brockhoff G, Schwarz-Furlan S, Agaimy A, Reichert TE, Rohrmeier C, Zenk J and Iro H: Predictors of cervical lymph node metastasis in salivary gland cancer. Head Neck 36: 517-523, 2014.

42. Zhang X, Zhang T, Yang K, Zhang M and Wang K: miR-486-5p suppresses prostate cancer metastasis by targeting Snail and regulating epithelial-mesenchymal transition. OncoTargets Ther 9: 6909-6914, 2016.

43. Kalluri R and Weinberg RA: The basics of epithelial-mesenchymal transition. J Clin Invest 119: 1420-1428, 2009.

This work is licensed under a Creative Commons Attribution-NonCommercial-NoDerivatives 4.0 International (CC BY-NC-ND 4.0) License. 